\title{
Development of Transgenic Escherichia coli with Improved Viability by Heterologous Expression of a Heat Shock Protein Gene from Carrot
} (Daucus carota L.)

\author{
Hanseul Park and Yeh-Jin Ahn ${ }^{1}$ \\ Department of Life Science, College of Natural Sciences, Sangmyung \\ University, 20 Hongjimun 2-gil, Jongno-gu, Seoul 03016, Korea
}

Additional index words. antifoam, Daucus carota, heat shock protein, heat stress, homologous recombination, lipoprotein gene promoter

\begin{abstract}
A small heat shock protein gene from carrot (Daucus carota L.), Hsp17.7, was inserted into the Escherichia coli chromosome by RecE/RecT-based homologous recombination to increase cell viability during industrial fermentation, which frequently encounters adverse growth conditions. DNA construct "lipoprotein (Lpp) gene promoter-Hsp17.7 gene-flippase recombination target (Frt) cassette" flanked by the sequences of the insertion site of the $E$. coli chromosome (yddE pseudogene) was generated by polymerase chain reaction (PCR). The transformed $E$. coli cell lines that heterologously expressed Hsp17.7 exhibited shorter lag phase, compared with control cell line under normal $\left(37^{\circ} \mathrm{C}\right)$, heat $\left(45^{\circ} \mathrm{C}\right)$, and antifoam conditions. Cell viability was higher in the transformed cell lines in the heat $\left(50^{\circ} \mathrm{C}\right.$, up to 2 -fold) and cold $\left(2^{\circ} \mathrm{C}\right.$, up to 1.7-fold) conditions. The soluble protein levels were also higher in the transformed $E$. coli cell lines by up to $\mathbf{2 0 \%}$, compared with control cell line in both stress conditions. The stress-tolerant transgenic cell lines developed in this study can contribute to more efficient and cost saving industrial cultivation of $E$. coli, which is most frequently used for recombinant protein production.
\end{abstract}

Escherichia coli is an important industrial microorganism that is most widely used for recombinant protein production (reviewed in Jana and Deb, 2005). However, during mass production, bacterial cell growth can be hindered by a number of factors. For example, elevated temperatures in bioprocesses can lead to denaturation of cellular and/or recombinant proteins (Mordukhova et al., 2008). Furthermore, the agitation of the cell culture can introduce gases that cause foaming, which can adversely affect bacterial cell growth and recombinant protein expression (Routledge, 2012). To inhibit the formation of foam, antifoams are routinely added to culture media. However, they can change cellular membrane permeability resulting in decreased cell growth.

In the present study, we aimed to recombine a small heat shock protein gene, Hsp 17.7, from carrot (D. carota 'Mussangochon') into the $E$. coli chromosome to increase the tolerance to adverse cultural conditions. Small heat shock proteins (sHsps; $12-42 \mathrm{kDa}$ in size) are found in virtually all living organisms during heat and other abiotic stress (Haslbeck and Vierling, 2015). They form oligomeric

Received for publication 26 Oct. 2015. Accepted for publication 13 Jan. 2016.

This research was supported by a 2015 Research Grant from Sangmyung University.

${ }^{1}$ Corresponding author. E-mail: yjahn@smu.ac.kr. complexes that consist of 12 to 24 subunits (Haslbeck et al., 2005). On exposure to stressful conditions, sHsps are dissociated into dimers and bind to protein substrates. Their primary function is that of a molecular chaperone that binds to partially unfolded protein substrates and prevents further denaturation and/or promotes correct refolding of the substrates. One of the characteristic structural features of sHsps is that they contain a conserved $\alpha$-crystallin domain at the $\mathrm{C}$-terminal end that plays important roles in oligomeric complex formation and molecular chaperone activity (Waters, 2013). The $\alpha$ - and $\beta$-crystallins are major proteins in the vertebrate eye lens, where they increase the refractive index and also play a protective role (Slingsby et al., 2013).

Plants have the greatest numbers of sHsps among all other organisms. There are $2 \mathrm{sHsps}$ in Archaea, 2 in E. coli, 2 in Saccharomyces cerevisiae, 10 in Homo sapiens, and 16 in Caenorhabditis elegans (Haslbeck et al., 2005). However, there are more than 30 different $s H s p$ genes in plants (Waters, 2013). Considering the sessile nature of plants, it is possible that diverse sHsps provide additional protection to plants against heat and other abiotic stress. Accordingly, plant sHsps can be valuable genetic resources to be used in the development of transgenic organisms with enhanced stress tolerance.

Hsp17.7 from carrot (D. carota), a model protein in this study, has been successfully used to develop transgenic organisms with improved stress tolerance: transgenic carrot cell lines (Malik et al., 1999) and potato plants (Ahn and Zimmerman, 2006) overexpressing Hsp17.7 exhibit enhanced tolerance to heat stress. Transgenic E. coli containing and expressing an Hsp17.7 gene in a bacterial plasmid vector exhibit improved cell viability and soluble protein levels under heat (Kim and Ahn, 2009) and other abiotic stress (Lee and Ahn, 2013; Song and Ahn, 2010).

Rather than using episomal expression vectors, such as plasmids, in this study, we introduced an Hsp 17.7 gene into the E. coli genome using RedE/RedT-mediated homologous recombination (Zhang et al., 2000). The insertion of a recombinant gene directly into the genome of the target organism has advantages over the use of episomal vectors: it provides experimental simplicity without having to undergo DNA restriction enzyme digestion and/or DNA ligation steps, which are prone to errors and DNA damage (Jacobus and Gross, 2015). Second, plasmids can carry up to $15 \mathrm{~kb}$ (Casali and Preston, 2003). However, DNA insert for homologous recombination can be generated by PCR without limitations on DNA sequences or sizes. Third, "plasmid instability" can cause losses in recombinant protein production (Friehs, 2004): the sequences of plasmids can be changed during replication, leading to possible losses in recombinant protein production and/ or fragmented proteins. In general, plasmids are burdensome for the bacterial cells because plasmid maintenance and replication requires energy of the host cells (Silva et al., 2012) Accordingly, there is a preference toward plasmid free cells during cultivation, which will lead to decreased production of recombinant proteins. Accordingly, direct targeting of the E. coli chromosome appears to be an efficient alternative to using plasmid vectors. By selecting proper promoters, one can control the conditions of recombinant gene expression between inducible and constitutive modes. We examined whether transformed $E$. coli containing an Hsp17.7 gene in its genome could be expressed by an $E$. coli promoter and increase cell viability under adverse culture conditions.

\section{Materials and Methods}

Insertion of an Hsp17.7 gene into the E. coli genome using homologous recombination. An Hsp17.7 gene was inserted into the genome of E. coli BL21 (DE3) using the Quick and Easy E. coli Gene Deletion Kit (Gene Bridges $\mathrm{GmbH}$, Heidelberg, Germany), which is based on RecE/RecT recombination (Zhang et al., 1998). The recombination in this study was targeted to the middle of the $y d d E$ pseudogene [National Center for Biotechnology Information (NCBI) accession no. NC_012971.2] in the E. coli genome. To induce high levels of $H s p 17.7$ expression in the transformed $E$. coli, the promoter region of Lpp gene (NCBI accession no.: NC_000913.2) was selected, because Lpp is one of the most abundant proteins in E. coli (Nakamura and Inouye, 1979). 
The DNA construct was designed to contain an "Lpp gene promoter-Hsp17.7 gene-Frt cassette" flanked by sequences of the insertion site, the $y d d E$ pseudogene. The Frt cassette contained a kanamycin selection marker. The stepwise generation of the DNA cassette is illustrated in Fig. 1. The Lpp gene promoter and Hsp17.7 gene were amplified from the E. coli and carrot (D. carota) genomic DNAs, respectively, by PCR (1 cycle at $98^{\circ} \mathrm{C}$ for $30 \mathrm{~s}$, followed by 35 cycles of $98{ }^{\circ} \mathrm{C}$ for $10 \mathrm{~s}, 55^{\circ} \mathrm{C}$ for $30 \mathrm{~s}$, and $72^{\circ} \mathrm{C}$ for $30 \mathrm{~s})$ using Lpp gene promoter-specific and Hsp17.7 gene-specific primers, respectively. The Frt cassette was also generated by PCR under the same conditions, with the exception of a longer extension step $\left(72{ }^{\circ} \mathrm{C}\right)$ for $1 \mathrm{~min} 30 \mathrm{~s}$ due to its long length. Phusion High-Fidelity PCR Master Mix with HF buffer polymerase (New England Biolabs, Ipswich, UK) was used for the accurate amplification of the DNA constructs. The PCR-amplified Lpp gene promoter and Hsp17.7 gene were combined by two-step extension PCR $\left(1\right.$ cycle at $98{ }^{\circ} \mathrm{C}$ for $30 \mathrm{~s}$, followed by 35 cycles of $98^{\circ} \mathrm{C}$ for $10 \mathrm{~s}, 72^{\circ} \mathrm{C}$ for $30 \mathrm{~s}$, and no annealing steps) without primers. The Lpp gene promoter, Hsp 17.7 fragment and Frt cassette were also combined by two-step extension PCR $\left(1\right.$ cycle at $98^{\circ} \mathrm{C}$ for $30 \mathrm{~s}$, followed by 35 cycles of $98{ }^{\circ} \mathrm{C}$ for $10 \mathrm{~s}, 72{ }^{\circ} \mathrm{C}$ for $1 \mathrm{~min} 45 \mathrm{~s}$, and no annealing steps) without primers. For the two-step extension PCR, 50-100 ng of each DNA fragment were used. The sequences of all the primers used in this study are presented in Table 1. Is-Lpp_F and Frt-Is_R primers contained sequences of the insertion site, the $y d d E$ pseudogene. The sequence of the final DNA fragment, i.e., "Lpp gene promoter-Hsp17.7 gene-Frt cassette" flanked by insertion site sequences, was confirmed by Macrogen (Seoul, Korea).

Transformation of the Red/ET plasmid into E. coli. The Red/ET expression plasmid to facilitate homologous recombination was inserted into E. coli BL21 (DE3) according to the protocol of the Quick and Easy E. coli Gene Deletion Kit (Gene Bridges $\mathrm{GmbH}$ ). The E. coli cells were cultured at $37{ }^{\circ} \mathrm{C}$ overnight with shaking. The bacterial culture was diluted 1:1000 with Luria-Bertani (LB) medium and cultured until the o.d. ${ }_{600}$ reached 0.6 and centrifuged at $1360 g_{\mathrm{n}}\left(4{ }^{\circ} \mathrm{C}\right)$ for $20 \mathrm{~min}$. The resulting bacterial cell pellet was dissolved in $1 \mathrm{~mL}$ of $10 \%$ glycerol and centrifuged under the abovementioned conditions and followed by the removal of the supernatant. After three rounds of washing, $30 \mu \mathrm{L}$ of bacterial cells were mixed with $20 \mathrm{ng} \cdot \mu \mathrm{L}^{-1} \mathrm{Red} / \mathrm{ET}$ expression plasmid and placed on ice for $30 \mathrm{~min}$ followed by electroporation $(1800 \mathrm{~V}, 25 \mu \mathrm{F}, 200 \mathrm{ohm}$; Gene Pulser X; Bio-Rad, Hercules, CA). After the addition of super optimal medium with glucose (SOC medium, $1 \mathrm{~mL}$ ), the cell cultures were then incubated at $30{ }^{\circ} \mathrm{C}$ for 70 min with shaking. The bacterial cells were then spread on solid LB medium containing $50 \mu \mathrm{g} \cdot \mu \mathrm{L}^{-1}$ ampicillin and incubated overnight.

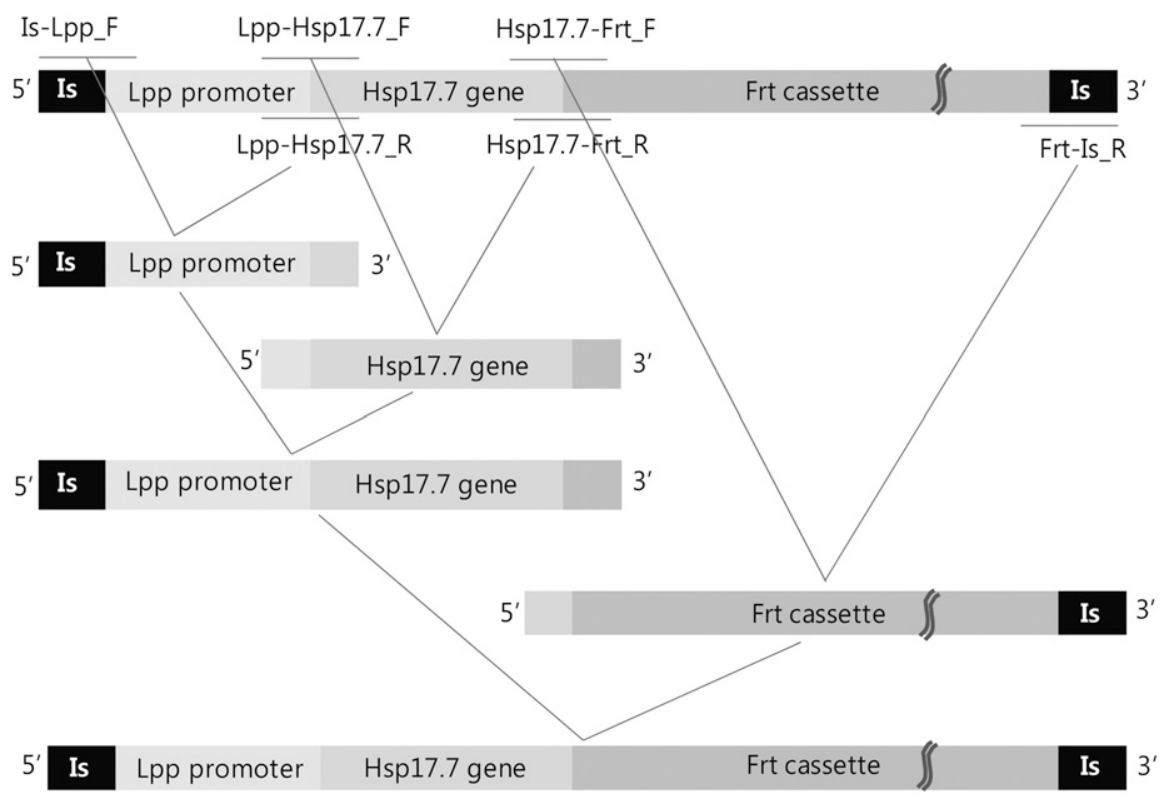

Fig. 1. Schematic diagram of the DNA construct generation. The lipoprotein gene [ $L p p$ gene; National Center for Biotechnology Information (NCBI) accession no.: NC_000913.2] promoter, an Hsp17.7 gene from carrot (Daucus carota L.; NCBI accession no.: X53851) and flippase-recombinase targets (Frt) cassette were generated by polymerase chain reaction (PCR) using three sets of specific primers whose sequences are shown in Table 1. The first and last primers (Is-Lpp_F and Frt-Is_R) contained sequences for insertion sites ( $y d d E$ pseudogene; NCBI accession no.: NC_012971.2). The DNA fragment was extended by PCR without annealing steps. The final DNA construct was introduced into the Escherichia coli genome using RecE/RecT-based homologous recombination as described in "Materials and Methods". Is = insertion site ( $y d d E$ pseudogene); Lpp = lipoprotein; Hsp = heat shock protein; Frt = flippase-recombinase targets; $\mathrm{F}=$ forward; $\mathrm{R}=$ reverse.

Table 1. Sequences of the primers used to generate the DNA construct containing Hsp17.7 gene for homologous recombination into the E. coli genome.

\begin{tabular}{|c|c|}
\hline Primers $^{\mathrm{z}}$ & Sequences $^{y}$ \\
\hline Is-Lpp_F & 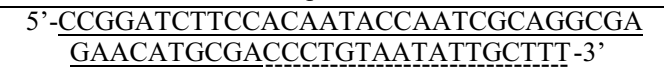 \\
\hline & Is (yddE) $\quad$ Lpp promoter \\
\hline Lpp-Hsp17.7_R & $\begin{array}{c}\text { 5'-TGGAATGATCGACATTATTAATACCCTCTA -3' } \\
\text { Hsp17.7 }\end{array}$ \\
\hline Lpp-Hsp17.7_F & 5'-TAGAGGGTATTAATAATGTCGATCATTCCA-3' \\
\hline & Lpp promoter \\
\hline Hsp17.7-Frt_R & $\begin{array}{l}\text { 5'-GAGAATAGGAACTTCTTAACCAGAAATATC-3' } \\
\text { Frt cassette }\end{array}$ \\
\hline Hsp17.7-Frt_F & $\begin{array}{c}\text { 5'-GATATTTCTGGTTAAGAAGTTCCTATTCTC-3' } \\
\text { Hsp17.7 } \\
\text { Frt cassette }\end{array}$ \\
\hline Frt-Is_R & $\begin{array}{l}\text { 5'-GGTACGCCGGGCTTTGAACTGCCGCTGGAGGGT } \\
\text { Is (yddE) } \\
\text { GAAGTACGCGCGAATACGACTCACTATAGGGC-3' }\end{array}$ \\
\hline
\end{tabular}

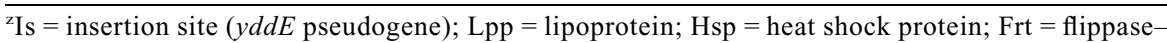
recombinase targets; $\mathrm{F}=$ forward; $\mathrm{R}=$ reverse.

${ }^{\mathrm{y}}$ The nucleotide sequences are underlined to show where the sequences were originated from.

Introduction of an Hsp17.7 gene into the E. coli genome. A surviving colony was chosen and cultured in LB medium containing $50 \mu \mathrm{g} \cdot \mu \mathrm{L}^{-1}$ ampicillin overnight at $37^{\circ} \mathrm{C}$ with shaking, diluted at 1:1000 with fresh $\mathrm{LB}$ medium with ampicillin, and cultured at $37{ }^{\circ} \mathrm{C}$ with shaking until the o.d.600 reached 0.6. L-arabinose (Sigma-Aldrich, St. Louis, MI) was added to a final concentration of $0.4 \%$, and the bacterial cells were cultured at $37{ }^{\circ} \mathrm{C}$ for $1 \mathrm{~h}$ with shaking followed by centrifugation at $1360 g_{\mathrm{n}}\left(4^{\circ} \mathrm{C}\right)$ for $20 \mathrm{~min}$. The cell pellet was then washed three times with $1 \mathrm{~mL}$ of $10 \%$ glycerol. Competent E. coli cells ( $30 \mu \mathrm{L}$ in $10 \%$ glycerol) were mixed with $3 \mu \mathrm{L}$ of the DNA construct "Lpp gene promoter-Hsp17.7 gene-Frt cassette" flanked by sequences of the insertion site ( $y d d E$ pseudogene; Fig. 1) and incubated on ice for $30 \mathrm{~min}$ followed by electroporation (1800 V, $25 \mu \mathrm{F}, 200 \mathrm{ohm})$. SOC medium $(1 \mathrm{~mL})$ was added, and the bacterial samples were cultured at $37^{\circ} \mathrm{C}$ for $3 \mathrm{~h}$ with shaking followed by spreading on solid LB medium containing kanamycin $\left(15 \mu \mathrm{g} \cdot \mu \mathrm{L}^{-1}\right.$ final concentration). The bacterial samples were then incubated at $37^{\circ} \mathrm{C}$ overnight, and the surviving colonies were obtained.

Confirmation of the Hsp17.7 gene insertion and protein expression in the transformed E. coli. Cell cultures were initiated from 10 surviving colonies, and genomic DNA was extracted using the ExiPrep Bacteria Genomic DNA kit (Bioneer, Daejeon, 

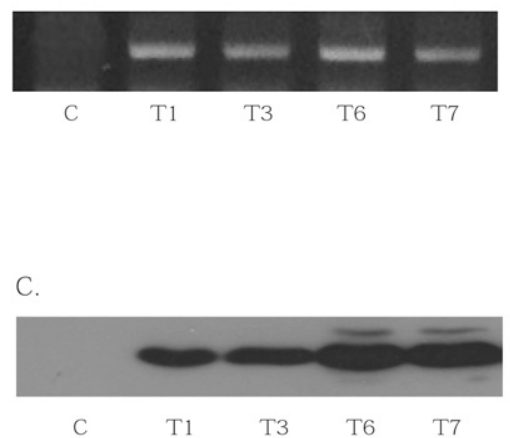

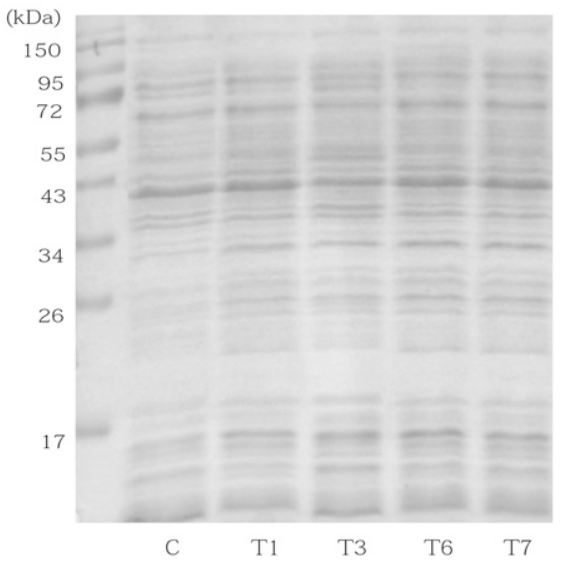

Fig. 2. Heterologous expression of Hsp17.7 in transformed Escherichia coli. (A) Genomic DNA was extracted from the transformed $E$. coli and control cell lines and subjected to polymerase chain reaction analysis using Hsp17.7 gene-specific primers. The size of the band was $\approx 500 \mathrm{bp}$. (B) The proteins were extracted from the transformed $E$. coli and control cell lines when the o.d.600 reached 0.6. Equal amounts of protein $(30 \mu \mathrm{g}$ per sample) were resolved on a $17 \%$ sodium dodecyl sulfate-polyacrylamide gel electrophoresis (SDS-PAGE) gel and stained using Coomassie blue dye. (C) Equal amounts of proteins (30 $\mu \mathrm{g}$ per sample) were resolved on a $17 \%$ SDS-PAGE gel and subjected to an immunoblot analysis using a polyclonal antibody raised against Hsp17.7. The size of the band was $\approx 18 \mathrm{kDa}$. The experiment was repeated three times, and representative images are shown. T1, T3, T6, and T7 = transformed cell lines heterologously expressing Hsp17.7; $\mathrm{C}=$ control cell line containing pRed/ET, which facilitates homologous recombination.
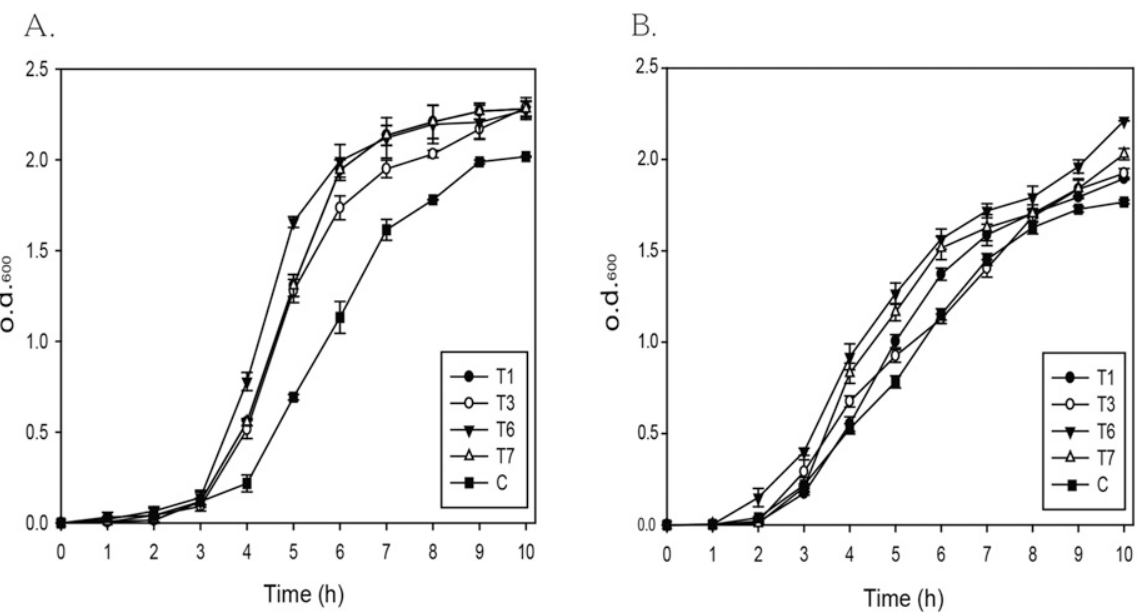

$$
\text { C. }
$$
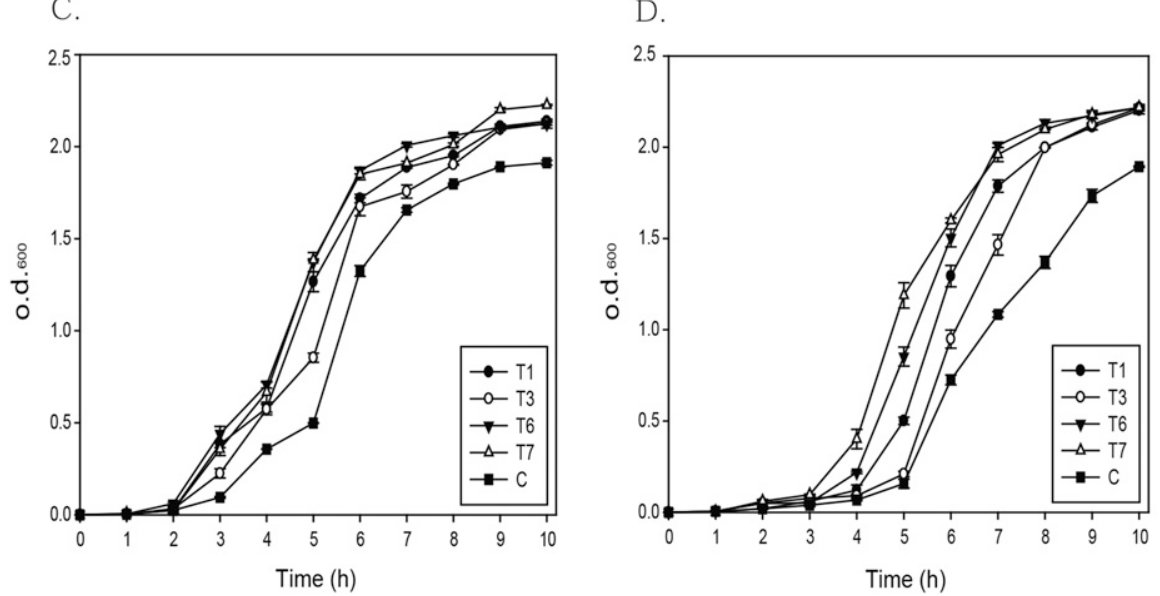

Fig. 3. Enhanced growth of the transformed Escherichia coli cell lines heterologously expressing Hsp17.7 under heat and antifoam conditions. Transformed E. coli and control cell lines were cultured at $(\mathbf{A})$ an optimal growth temperature $\left(37^{\circ} \mathrm{C}\right)$ and $(\mathbf{B})$ an elevated temperature $\left(45^{\circ} \mathrm{C}\right)$ for $10 \mathrm{~h}$. The bacterial cell lines were also cultured in the presence of an antifoam (Ppg 2000), (C) at $1 \mathrm{~mL} \cdot \mathrm{L}^{-1}$ and (D) at $2 \mathrm{~mL} \cdot \mathrm{L}^{-1}$. Cell growth was examined by measuring the $0 . \mathrm{d}_{600}$ at $1 \mathrm{~h}$ intervals. The error bars indicate the standard errors of the means. T1, T3, T6, and T7 = transformed cell lines heterologously expressing Hsp17.7; $\mathrm{C}=$ control cell line containing $\mathrm{pRed} / \mathrm{ET}$, which facilitates homologous recombination.

Korea). PCR ( 1 cycle at $98{ }^{\circ} \mathrm{C}$ for $30 \mathrm{~s}$, followed by 35 cycles of $98^{\circ} \mathrm{C}$ for $10 \mathrm{~s}, 55^{\circ} \mathrm{C}$ for $30 \mathrm{~s}$, and $72{ }^{\circ} \mathrm{C}$ for $30 \mathrm{~s}$ ) was performed on the genomic DNA with Hsp17.7 genespecific primers (Lpp-Hsp17.7_F and Hsp17.7-Frt_R; Table 1) using the Accupower ProFi Taq PCR Premix (Bioneer). The control cell line contained only the pRed/ET plasmid.

To examine the heterologous accumulation of Hsp17.7 protein in the transformed E. coli, sodium dodecyl sulfate-polyacrylamide gel electrophoresis (SDS-PAGE; Laemmle, 1970) and immunoblot analyses were performed as previously described (Ko et al., 2015). Briefly, transformed $E$. coli cells were cultured overnight, diluted at 1:1000 with LB medium containing kanamycin $\left(15 \mu \mathrm{g} \cdot \mu \mathrm{L}^{-1}\right)$, and cultured at $37^{\circ} \mathrm{C}$ until the o.d. 600 reached 0.6. After centrifugation at $1360 g_{\mathrm{n}}$ at $4{ }^{\circ} \mathrm{C}$ for $20 \mathrm{~min}$, the resulting pellet was dissolved in $3 \mathrm{~mL}$ protein extraction buffer $(25 \mathrm{~mm}$ Tris$\mathrm{HCl} \mathrm{pH} 7.5,300 \mathrm{~mm} \mathrm{NaCl}$, and $3 \mathrm{~mm}$ $\beta$-mercaptoethanol) and sonicated $(420 \mathrm{~W}$ and $20 \mathrm{kHz}$ for a total of $4 \mathrm{~min}$ and $40 \mathrm{~s}$ with repeated bursts of $10 \mathrm{~s}$ of ultra-sonication and $30 \mathrm{~s}$ pauses) using a Sonosmasher (S\&T Science, Seoul, Korea) and followed by centrifugation at $20,900 g_{n}$ for $1 \mathrm{~h}$. The resulting supernatant was quantified by Bradford assay (1976). Equal amounts of the bacterial proteins $(30 \mu \mathrm{g})$ were resolved on a $17 \%$ SDS-PAGE gel and either stained with Coomassie blue dye (Bio$\mathrm{Rad})$ or transferred to a nitrocellulose membrane (Hybond ECL; GE Healthcare, Piscataway, NJ) followed by an immunoblot analysis with a polyclonal antibody raised against Hsp17.7 using the ECL Plus system (GE Healthcare). The experiment was repeated three times.

Cell growth under heat and antifoam conditions. Transformed E. coli expressing Hsp17.7 and control cell lines were cultured at $37{ }^{\circ} \mathrm{C}$ overnight, diluted $1: 1000$ as stated above, and then cultured under heat $\left(45^{\circ} \mathrm{C}\right)$ and antifoam [polypropylene glycol (Ppg) 2000 up to $2 \mathrm{~mL} \cdot \mathrm{L}^{-1}$; Routledge, 2012] conditions with shaking. The o.d.600 was measured at hour intervals for up to $10 \mathrm{~h}$. The experiment was repeated three times with three replicates.

Cell viability of the transformed E. coli under heat and cold conditions. Transformed E. coli expressing Hsp17.7 and control cell lines were cultured at $37{ }^{\circ} \mathrm{C}$ overnight and diluted at 1:1000 as stated above. When the o.d. 600 reached 0.6 , the bacterial cells were then transferred to heat $\left(50{ }^{\circ} \mathrm{C}\right)$ or cold $\left(2{ }^{\circ} \mathrm{C}\right)$ conditions and cultured for $60 \mathrm{~min}$ and $10 \mathrm{~d}$, respectively. The cell cultures were then diluted to $1: 1000$ with LB medium containing kanamycin $\left(15 \mu \mathrm{g} \cdot \mu \mathrm{L}^{-1}\right)$ and spread on LB medium containing kanamycin. After overnight incubation at $37^{\circ} \mathrm{C}$, the numbers of surviving colonies were counted and the survival percentages were calculated. The experiment was repeated three times with five replicates.

Molecular chaperone function of heterologous Hsp17.7 under heat and cold stress. Overnight cell culture, protein extraction, and quantification of the transformed E. coli expressing Hsp17.7 and the control 


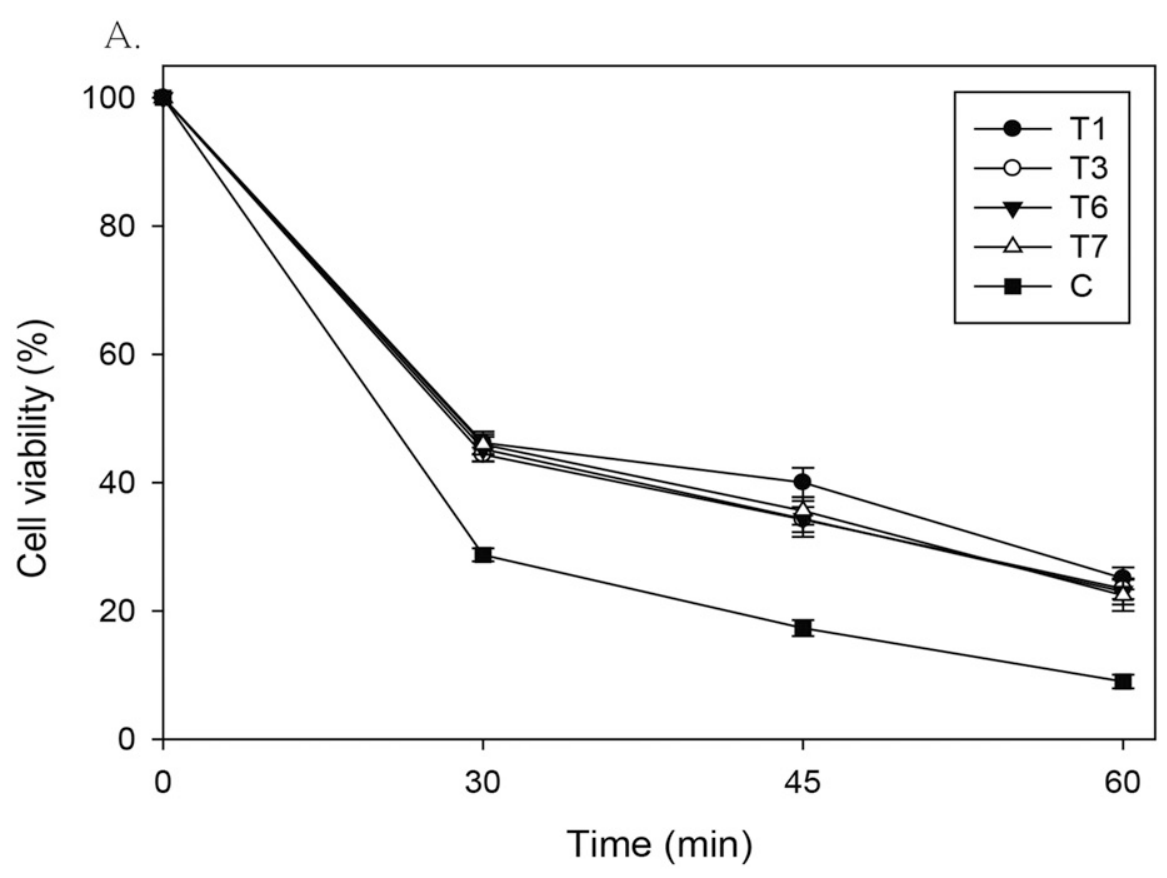

B.

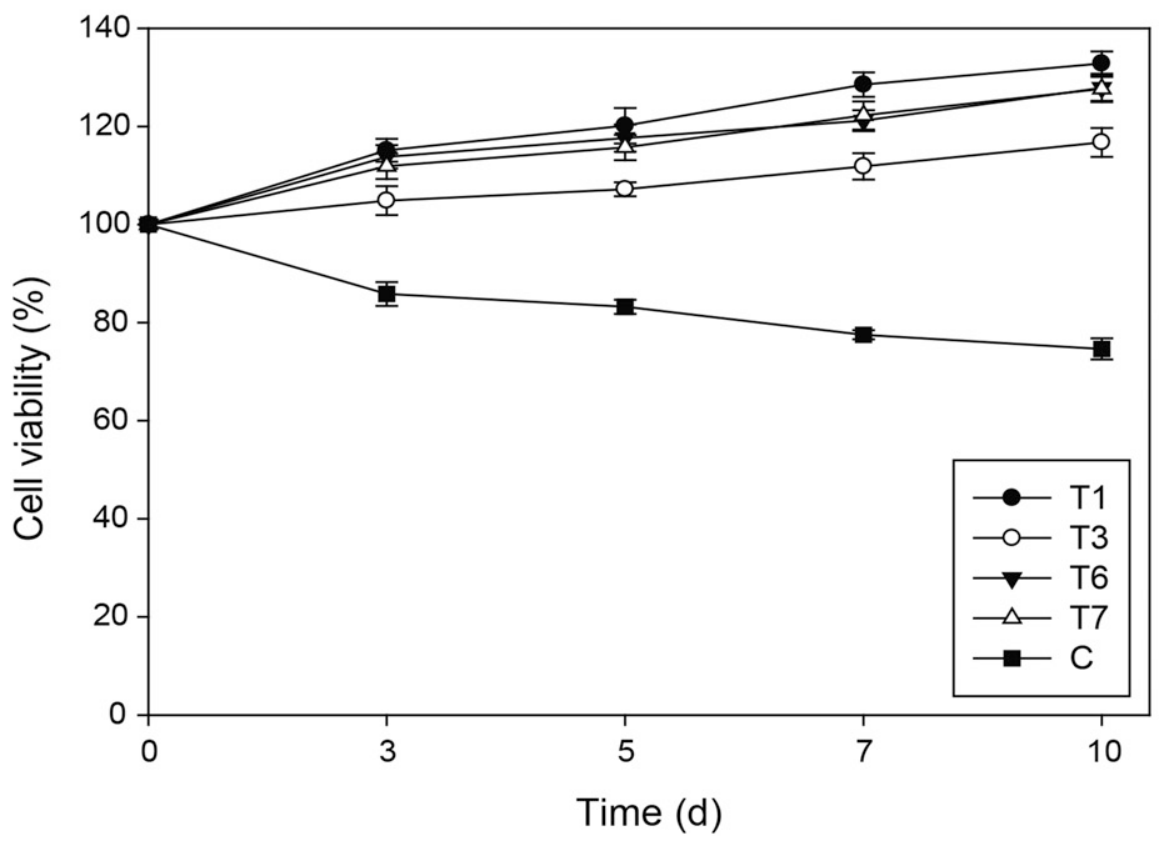

Fig. 4. Enhanced cell viability in the transformed Escherichia coli heterologously expressing Hsp17.7 in the heat and cold conditions. Transformed E. coli and control cell lines were cultured until the o.d. 600 reached 0.6 and then exposed to $(\mathbf{A})$ heat $\left(50^{\circ} \mathrm{C}\right)$ or $(\mathbf{B})$ cold $\left(2{ }^{\circ} \mathrm{C}\right)$ conditions for $60 \mathrm{~min}$ and $10 \mathrm{~d}$, respectively. The $E$. coli cell cultures were diluted $1: 10^{-6}$ with fresh Luria-Bertani (LB) medium containing kanamycin $\left(15 \mu \mathrm{g} \cdot \mu \mathrm{L}^{-1}\right)$ and spread on solid LB medium containing kanamycin. After overnight incubation at $37^{\circ} \mathrm{C}$, the numbers of the surviving colonies were counted, and the survival percentages were calculated. The error bars indicate the standard errors of the means. T1, T3, T6, and $\mathrm{T} 7$ = transformed cell lines heterologously expressing Hsp17.7; C = control cell line containing pRed/ ET, which facilitates homologous recombination.

cell lines were performed as stated above. Equal amounts of bacterial protein $(2 \mathrm{mg})$ were incubated in heat $\left(52{ }^{\circ} \mathrm{C}\right)$ or cold $\left(2{ }^{\circ} \mathrm{C}\right)$ conditions for $60 \mathrm{~min}$ or $10 \mathrm{~d}$, respectively. The protein samples were then centrifuged at $20,900 g_{\mathrm{n}}$ for $1 \mathrm{~h}$, and the amount of soluble protein in the supernatants was quantified by Bradford assay (1976). The percentages of soluble proteins in the stressful conditions were calculated. used to carry and express recombinant genes. However, there have been improvements in the approaches to directly engineering the bacterial genome using homologous recombination (Zhang et al., 2000). These approaches allow for DNA constructs to be inserted without the restriction of insertion sites, which enables various types of chromosomal DNA modifications, such as gene cloning, gene deletion, and artificial chromosome generation. In E. coli, bacteriophage-encoded recombination proteins (RecE and RecT) efficiently recombine sequences with homologies as short as 35 to 50 bases (Zhang et al., 1998).

A $s H s p$ gene from carrot (D. carota), $H s p 17.7$, was inserted into the E. coli genome using RecE/RecT-mediated homologous recombination. To maximize the heterologous expression of Hsp17.7 in transformed E. coli, we used the promoter of Lpp gene, which is expressed very abundantly in E. coli (Nakamura and Inouye, 1979). The DNA construct " $L p p$ gene promoter-Hsp17.7 gene-FRT cassette" flanked by sequences of the insertion site ( $y d d E$ pseudogene) was successfully generated by PCR and inserted into E. coli BL21 (DE) by electroporation. The treated $E$. coli cells were then spread on LB plates containing kanamycin. After overnight incubation, 10 colonies were selected and subjected to PCR analysis with Hsp17.7-specific primers. Only four colonies exhibited positive bands at $\approx 500$ base pair (bp) (Hsp17.7 gene $=474$ bp; Fig. 2A), which suggested the successful insertion of the Hsp17.7 gene. DNA sequencing further confirmed that the DNA construct containing an Hsp17.7 gene was successfully inserted into the target insertion site (data not shown).

To verify the Hsp17.7 protein accumulation in the transformed $E$. coli cell lines, proteins were extracted and subjected to SDS-PAGE and immunoblot analysis using a polyclonal antibody raised against Hsp 17.7. The overall protein pattern was similar in the transformed E. coli cell lines and control cell line that contained the $\mathrm{pRed} / \mathrm{ET}$ plasmid only (Fig. 2B). Immunoblot analysis revealed the heterologous expression of Hsp17.7 in the transformed E. coli cell lines (Fig. 2C). Protein bands appeared at $\approx 18 \mathrm{kDa}$.

Our results revealed that the $H s p 17.7$ gene was successfully integrated into the $E$. coli genome through RecE/RecT-based homologous recombination and successfully expressed into the protein. Our study provides valuable information about the genomic DNA manipulation and recombinant protein production in $E$. coli. Other recombinant genes will also be able to be introduced into the $y d d E$ pseudogene site in the E. coli genome and expressed under the control of the Lpp gene promoter. To further increase recombinant gene expression, it is possible to screen more insertion sites in the $E$. coli chromosome. We examined two other insertions sites [in front of the $r h s E$ gene (NCBI accession no.: NC_000913.3) and in the middle of the $y d b A$ pseudogene (NCBI accession no.: NC_2847750)] in the E. coli genome to express $H_{s p 17.7}$ gene. This cassette was successfully inserted into the E. coli genome; however, 

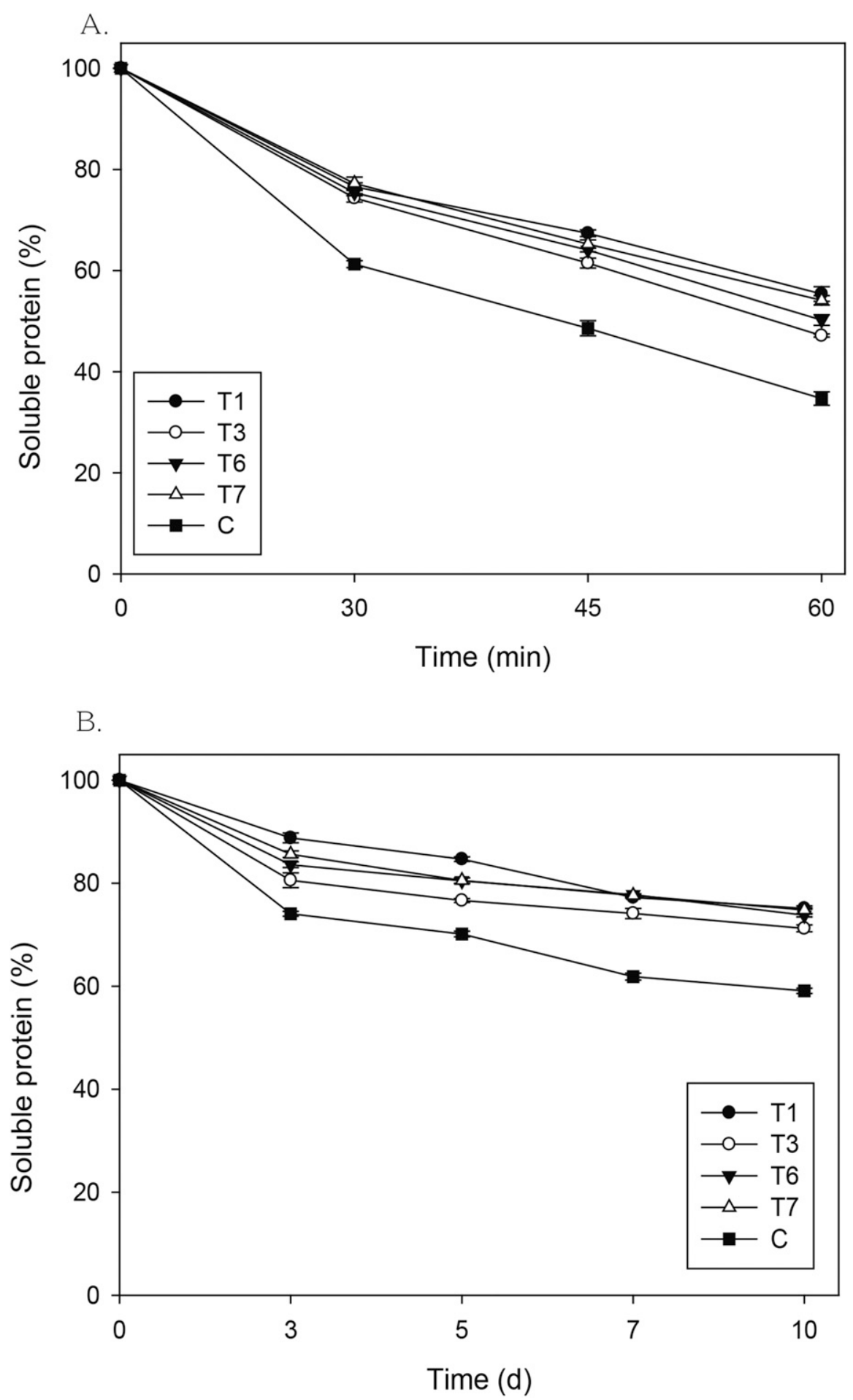

Fig. 5. Enhanced protein solubility in the transformed Escherichia coli heterologously expressing Hsp17.7 in heat and cold conditions. The transformed $E$. coli and control cell lines were cultured until the o.d. ${ }_{600}$ reached 0.6 . The total proteins were extracted using ultra-sonication. Equal amounts of bacterial protein $(2 \mathrm{mg})$ were incubated in $(\mathbf{A})$ heat $\left(52^{\circ} \mathrm{C}\right)$ or $(\mathbf{B})$ cold $\left(2^{\circ} \mathrm{C}\right)$ conditions for $60 \mathrm{~min}$ or $10 \mathrm{~d}$, respectively. After ultra-centrifugation, the amounts of soluble proteins in the supernatants were quantified, and the percentages of soluble protein were calculated. The error bars indicate the standard errors of the means. $\mathrm{T} 1, \mathrm{~T} 3, \mathrm{~T} 6$, and $\mathrm{T} 7=$ transformed cell lines heterologously expressing Hsp17.7; C = control cell line containing pRed/ET, which facilitates homologous recombination.

the protein did not accumulate (data not shown), which suggests that the recombination site is very important for heterologous gene expression. In addition, by modifying the promoter sequence, it will also be possible to further increase the expression level of the recombinant gene and control the gene expression in terms of whether it is constitutive or conditional. For example, using the heat shock gene promoter from one of the $H s p$ genes in $E$. coli would allow for recombinant gene expression only under stressful conditions.
Increased cell growth of transformed E. coli under heat and antifoam conditions. To examine whether the genomic insertion of the Hsp17.7 gene and its heterologous expression could confer tolerance to adverse conditions, the growth of the transformed E. coli and control cell lines were measured under heat and antifoam conditions. Under the normal growth condition $\left(37^{\circ} \mathrm{C}\right)$, all of the transformed cell lines that heterologously expressed Hsp17.7 exhibited shorter lag phase compared with the control (Fig. 3A). An elevation in the temperature $\left(45^{\circ} \mathrm{C}\right)$ decreased the growth of all of the cell lines examined (Fig. 3B). However, the transformed $E$. coli cell lines also exhibited shorter lag phase than the control. The addition of an antifoam agent (Ppg 2000) decreased the growth of all the cell lines examined (Fig. 3C and D). However, at 1 and $2 \mathrm{~mL} \cdot \mathrm{L}^{-1}$ Ppg 2000, which are typical concentrations in $E$. coli culture when the addition of Ppg 2000 is needed, the transformed $E$. coli cell lines exhibited shorter lag phase than the controls. In the transformed E. coli cell lines in the presence of $2 \mathrm{~mL} \cdot \mathrm{L}^{-1} \mathrm{Ppg}$ 2000 treatment, the lag phase was shorter by up to $\approx 2 \mathrm{~h}$ than the control cell line (Fig. 3D). During stationary phase, the o.d.600 of the transformed $E$. coli cell lines was higher than that of the control by $0.3-0.5$ in all of the growth conditions examined.

Our result suggests that heterologously expressed Hsp17.7 functions to improve the growth of the transformed $E$. coli cell lines even in the absence of stress. Previous studies have reported that some sHSPs were expressed under normal growth conditions, mostly at specific developmental stages of plants, such as during embryogenesis, seed maturation, pollen development, and fruit maturation (reviewed in Waters, 2013). Hsp17.7 was also accumulated in dry seeds, seedlings (up to $14 \mathrm{~d}$ after imbibition), and flowers under normal growth conditions (Kim and Ahn, 2010). In addition to preventing protein denaturation under stress conditions, molecular chaperones, such as sHSPs, play a role in maintaining protein homeostasis in nonstressed cells. They facilitate the folding of newly synthesized proteins, the assembly/disassembly of other macromolecular complexes, and the translocation of proteins across membranes of intracellular compartments (Cox et al., 2014). It is possible that shorter lag phage of transformed E. coli cell lines in the absence of stress, compared with the control (Fig. 3A), may result from higher levels of protein homeostasis by heterologously expressed Hsp17.7.

Under heat stress, the heterologous expression of sHsps in E. coli increased cell growth and viability. The overexpression of sHsps in E. coli, IbpA and IbpB, increased viability under heat and oxidative stress (Kitagawa et al., 2000). The sHsp from C. elegans Hsp17 increased the viability of the transformed $E$. coli by maintaining the cell membrane stability (Ezemaduka et al., 2014). However, most of these studies used episomal vectors to carry and express 
recombinant $s H s p$ genes. Our study reported that a $s H s p$ gene from plants can successfully be inserted into the $E$. coli genome and expressed to confer tolerance to adverse growth conditions, such as heat and antifoam.

Increased cell viability and protein solubility by Hsp 17.7. The primary function of Hsps is to act as a molecular chaperone to maintain the solubility of cellular proteins, which contributes to increased cell viability under stressful conditions (Sun et al., 2002). In this study, the transformed $E$. coli cell lines containing the Hsp17.7 gene from carrot (D. carota) and the control cell line were subjected to heat and cold conditions. Colony forming units and protein solubility were measured to examine whether the heterologously expressed Hsp 17.7 could increase the survival rates of the transformed $E$. coli and function as a molecular chaperone to maintain the soluble protein levels under adverse growth conditions.

Elevations in temperature $\left(50{ }^{\circ} \mathrm{C}\right)$ decreased the cell viabilities of all of the examined cell lines (Fig. 4A). However, the transformed cell lines heterologously expressing Hsp17.7 exhibited more than 2-fold greater levels of surviving cells, compared with the control cell line. At $45 \mathrm{~min}$, the transformed cell line T1 exhibited a $46 \%$ survival rate, compared with the $22 \%$ in the control. Extended cold treatment $\left(2{ }^{\circ} \mathrm{C}\right)$ decreased the viability of the control cell line to $75 \%$ after $10 \mathrm{~d}$ (Fig. 4B). However, the transformed cell lines gradually increased their cell survival rates to $133 \%$ (cell line T1).

Both thermal stresses decreased soluble protein levels in the transformed E. coli and the control cell line (Fig. 5). However, the transformed $E$. coli cell lines exhibited levels of soluble proteins that were up to $20 \%$ greater in both conditions. Our results revealed that heterologously expressed Hsp17.7 from carrot (D. carota) could function as a molecular chaperone to increase protein solubility in heat and cold stress conditions, possibly resulting in increased cell viability. Purified Hsp17.7 protected the model substrate malate dehydrogenase at $50{ }^{\circ} \mathrm{C}$ in vitro, which proved its molecular chaperone function (data not shown).

Unlike the heat stress, which caused decreases both in cell viability and protein solubility of transformed $E$. coli heterologously expressing Hsp17.7, under the cold condition, there was a slight increase in viability of transformed E. coli cell lines (up to $133 \%$, Fig. 4B), although protein solubility decreased to $73 \%$ (Fig. 5B). Low temperatures mainly cause a decrease in membrane fluidity and in transcription/translation efficiencies by stabilization of secondary structures of nucleic acids (reviewed in Phadtare, 2004). It is possible that heterologously expressed Hsp17.7 may play a role in these processes in the transformed $E$. coli cell lines under cold stress.

In this study, an $H s p 17.7$ gene from carrot (D. carota) was successfully inserted into the
E. coli genome using homologous recombination and expressed under the control of the $L p p$ gene promoter from $E$. coli. The insertion of a recombinant gene into the $E$. coli genome provided more stable recombinant gene expression compared with the use of episomal vectors. The information about the insertion site ( $y d d E$ gene) and promoter ( $L p p$ gene promoter) could be used to express other recombinant genes. Furthermore, by manipulating the insertion site and the promoter sequences, it will be possible to control the expression level (high or low) and/or the expression condition (constitutive or conditional) of the recombinant gene. The heterologous expression of Hsp17.7 increased the growth, cell viability, and protein solubility in the transformed E. coli in heat, cold, and antifoam conditions, which suggests that Hsp17.7 is a useful genetic resource that confers tolerance to adverse growth conditions. The transformed $E$. coli cell lines developed in this study could be used in large-scale culture for industrial production and provide higher cell growth and viability.

\section{Literature Cited}

Ahn, Y.J. and J.L. Zimmerman. 2006. Introduction of the carrot HSP17.7 into potato (Solanum tuberosum L.) enhances cellular membrane stability and tuberization in vitro. Plant Cell Environ. 29:95-104.

Bradford, M.M. 1976. A rapid and sensitive method for the quantitation of microgram quantities of protein utilizing the principle of protein-dye binding. Anal. Biochem. $72: 248-254$.

Casali, N. and A. Preston. 2003. E. coli plasmid vectors: Methods and applications. Humana Press, Totowa, NJ.

Cox, D., J.A. Carver, and H. Ecroyd. 2014. Preventing $\alpha$-synuclein aggregation: The role of the small heat-shock molecular chaperone proteins. Biochim. Biophys. Acta 1842: $1830-1843$

Ezemaduka, A.N., J. Yu, X. Shi, K. Zhang, C.C. Yin, X. Fu, and Z. Chang. 2014. A small heat shock protein enables Escherichia coli to grow at a lethal temperature of $50^{\circ} \mathrm{C}$ conceivably by maintaining cell envelope integrity. J. Bacteriol. 196:2004-2011.

Friehs, K. 2004. Plasmid copy number and plasmid stability. Adv. Biochem. Engin/Biotechnol. 86:47-82.

Haslbeck, M., T. Franzmann, D. Weinfurtner, and J. Buchner. 2005. Some like it hot: The structure and function of small heat-shock proteins. Natl. Struct. Mol. Biol. 12:842-846.

Haslbeck, M. and E. Vierling. 2015. A first line of stress defense: Small heat shock proteins and their function in protein homeostasis. J. Mol. Biol. 427:1537-1548.

Jacobus, A.P. and J. Gross. 2015. Optimal cloning of PCR fragments by homologous recombination in Escherichia coli. PLoS One 16:e0119221.

Jana, S. and J.K. Deb. 2005. Strategies for efficient production of heterologous proteins in Escherichia coli. Appl. Microbiol. Biotechnol. 67:289-298.

Kim, H. and Y.J. Ahn. 2009. Expression of a gene encoding the carrot HSP17.7 in Escherichia coli enhances cell viability and protein solubility under heat stress. HortScience 44:866-869.

Kim, H. and Y.J. Ahn. 2010. Carrot heat shock protein DcHsp17.7 is present in various tissues without thermal stress and is regulated by tissue type and thermal stress. Hort. Environ. Biotechnol. 51:141-145.

Kitagawa, M., Y. Matsumura, and T. Tsuchido. 2000. Small heat shock proteins, IbpA and $\mathrm{IbpB}$, are involved in resistances to heat and superoxide stresses in Escherichia coli. FEMS Microbiol. Lett. 184:165-171.

Ko, E., H. Park, and Y.J. Ahn. 2015. Carrot (Daucus carota L.) heat shock protein 70 gene (DcHsp 70) confers tolerance to heat or cold stress in E. coli cells. J. Hort. Sci. Biotechnol. 90:451-458.

Laemmle, U.K. 1970. Cleavage of structural proteins during the assembly of the head of bacteriophage T4. Nature 227:680-685.

Lee, J. and Y.J. Ahn. 2013. Heterologous expression of a carrot small heat shock protein increased Escherichia coli viability under lead and arsenic stresses. HortScience 48: 1323-1326.

Malik, M.K., J.P. Slovin, C.H. Hwang, and J.L. Zimmerman. 1999. Modified expression of a carrot small heat shock protein gene, Hsp 17.7, results in increased or decreased thermotolerancedouble dagger. Plant J. 20:89-99.

Mordukhova, E.A., H. Lee, and J.G. Pan. 2008. Improved thermostability and acetic acid tolerance of Escherichia coli via directed evolution of homoserine o-succinyltransferase. Appl. Environ. Microbiol. 74:7660-7668.

Nakamura, K. and M. Inouye. 1979. DNA sequence of the gene for the outer membrane lipoprotein of E. coli: An extremely AT-rich promoter. Cell 18:1109-1117.

Phadtare, S. 2004. Recent developments in bacterial cold-shock response. Curr. Issues Mol. Biol. 6:125-136.

Routledge, S.J. 2012. Beyond de-foaming: The effects of antifoams on bioprocess productivity. Comput. Struct. Biotechnol. J. 3: e201210014

Silva, F., J.A. Queiroz, and F.C. Domingues. 2012. Evaluating metabolic stress and plasmid stability in plasmid DNA production by Escherichia coli. Biotechnol. Adv. 30:691-708.

Slingsby, C., J.W. Graeme, and A.R. Clark. 2013. Evolution of crystallins for a role in the vertebrate eye lens. Protein Sci. 22:367380

Song, N. and Y.J. Ahn. 2010. DcHsp17.7, a small heat shock protein from carrot, is upregulated under cold stress and enhances cold tolerance by functioning as a molecular chaperone. HortScience 45:469-474.

Sun, W., M. van Montagu, and N. Verbruggen. 2002. Small heat shock proteins and stress tolerance in plants. Biochim. Biophys. Acta 1577:1-9.

Zhang, Y., F. Buchholz, J.P. Muyrers, and A.F. Stewart. 1998. A new logic for DNA engineering using recombination in Escherichia coli. Natl. Genet. 20:123-128.

Zhang, Y., J.P. Muyrers, G. Testa, and A.F. Stewart. 2000. DNA cloning by homologous recombination in Escherichia coli. Natl. Biotechnol. 18:1314-1317.

Waters, E.R. 2013. The evolution, function, structure, and expression of the plant sHSPs. J. Expt. Bot. 64:391-403. 